\title{
Trend Rooftop Restaurant And Bar Sebagai Daya Tarik Wisata Kuliner di DKI Jakarta
}

\author{
Cindy Larini a, 1 , Ida Bagus Suryawan a, 2 \\ 1 Cindylarini@gmail.com,2idabagussuryawan@unud.ac.id \\ a Program Studi S1 Destinasi Pariwisata,Fakultas Pariwisata,Universitas Udayana, Jl. Dr. R. Goris, Denpasar, Bali 80232 Indonesia
}

\section{Abstract}

In the middle of the city is really hard to find a tourist attraction based on nature because usually the city is full of buildings. However, it is not impossible to build a tourist attraction in a city. Nowadays, there are many buildings that being used as tourist attraction based on rooftop restaurant and bar. This phenomenon is not only happened in Indonesia, but also becoming urban tourism trend in the world.

The data for this observation is collected by doing an observation, in-depth interview with the informants, and researching on archive collections about rooftop restaurant and bar. The informants were determined based on purposive sampling, where the informants were selected based on certain specification. The informants of this observation are The Cloud Lounge \& Dining Jakarta's manager, SKYE Bar \& Restaurant's manager, and Henshin's supervisor.

The result of this observation are tourist attraction in those rooftop restaurants and bars, and the development on each of the rooftop restaurants and bars every years. The development on rooftop restaurant and bar were analyzed by using fishbone analysis to see the impact of the changes on each rooftop restaurants and bars.

Key words: Urban Tourism, Tourist Attraction, Rooftop Restaurant and Bar, Fishbone Analysis.

\section{PENDAHULUAN}

Wisatawan yang memiliki agenda kunjungan ke kota umumnya memiliki berbagai macam kegiatan diantaranya berbelanja, berekreasi bersama keluarga dan kerabat, melakukan kegiatan bisnis, serta mengunjungi sanak saudara. Wisata atau pariwisata perkotaan memiliki karakteristik lain yang khas yaitu wisatawan perkotaan menggunakan fasilitas perkotaan sebagai daya tarik wisatanya (Law, 1996). Seperti contoh pada Daerah Khusus Ibukota Jakarta (DKI Jakarta), di mana lokasi seperti taman kota, restoran, pusat perbelanjaan, dan lain sebagainya selain digunakan oleh warga Jakarta tetapi juga merupakan daya tarik tersendiri bagi warga yang berasal dari luar wilayah Jakarta, seperti wisatawan.

Wisata perkotaan menyajikan wisata belanja, kuliner, budaya, sejarah, dan wisata yang sedang berkembang dan tren saat ini adalah wisata foto. Terbatasnya sumber daya alam di wilayah perkotaan membuat wisata perkotaan lebih mengembangkan dan memfokuskan pada wisata buatan. Selain dari wisata buatan wisatawan juga disuguhkan pemandangan gedung-gedung pencakar langit yang mampu memberikan daya tarik tersendiri. Gedung-gedung tersebut juga dapat digunakan oleh wisatawan untuk melihat pemandangan kota dari ketinggian. Salah satu bagian gedung yang dapat digunakan untuk melihat pemandangan kota adalah lantai tertinggi gedung yaitu rooftop.

Pada umumnya bagian rooftop dari gedung tidak diperkenankan digunakan untuk umum, tetapi jika peluang ini dapat dimanfaatkan dengan baik maka akan menjadi destinasi wisata baru yang akan digemari khususnya bagi wisatawan millennial. Menjawab perkembangan dan persaingan wisata saat ini membuat para pelaku bisnis pariwisata mengembangkan inovasi dan kreasinya dengan memanfaatkan rooftop sebagai magnet wisata baru. Rooftop tersebut dimanfaatkan sebagai restaurant, bar, lounge, dan lain sebagainya. Wisatawan akan mendapatkan sensasi pengalaman dan suasana yang menarik dan spektakuler, seperti menyantap makan malam dengan ditemani pemandangan malam kota, serta diiringi lantunan musik yang sesuai dengan 
suasana. Berdasarkan informasi yang diterbitkan oleh beberapa artikel seperti Tour Scanner, artikel dari Harper 's Bazaar, dan artikel dari CNN Travel dapat dicermati bahwa terdapat berbagai negara yang sudah menggunakan konsep rooftop restaurant diantaranya Amerika, Inggris, Perancis, Singapura, Jepang, dan lain sebagainya, termasuk sudah diterapkan di Indonesia.

Daerah Khusus Ibukota Jakarta selain sebagai pusat pemerintahan, DKI Jakarta juga menyimpan keunikannya tersendiri sehingga menjadi magnet wisata bagi para wisatawan. Kota Jakarta memiliki warisan wisata budaya, alam, dan juga wisata buatan. Tetapi permasalahan yang terjadi adalah pembangunan Kota Jakarta yang sangat pesat menyebabkan terbatasnya ketersediaan lahan sehingga wisata berbasis alam menjadi sangat terbatas. Berdasarkan hal ini Kota Jakarta lebih memprioritaskan pada wisata buatan, sehingga Jakarta mempunyai obyek wisata yang dapat dikunjungi. Tren pariwisata yang berkembang saat ini adalah wisata makanan atau kuliner yang ditempatkan di lantai tertinggi pada gedung pencakar langit.

Rooftop restaurant and bar merupakan terobosan tujuan wisata baru yang diharapkan mampu menjadi destinasi wisata favorit di Kota Jakarta. Menurut hasil survey dan pengamatan yang dilakukan peneliti pada tahun 2018 dan juga zomato menunjukkan bahwa setidaknya terdapat 46 rooftop restaurant \& bar di Kota Jakarta dan 3 (tiga) diantaranya terletak diatas lantai 40.

Mencermati pada banyaknya jumlah rooftop restaurant and bar yang berada dan telah beroperasi di Kota Jakarta, maka disaring dan dipilih 3 (tiga) rooftop restaurant and bar yang menjadi fokus penelitian yang didasarkan pada perkembangan jumlah kunjungan serta berdasarkan alasan ketinggian. Ketiga rooftop restaurant and bar tersebut ditunjukkan pada Tabel 1 berikut:
TABEL 1. Daftar Nama 3 (Tiga) Rooftop Restaurant \& Bar di DKI Jakarta

\begin{tabular}{|c|c|c|}
\hline No & Nama Rooftop Restaurant & Ketinggian \\
\hline 1 & $\begin{array}{c}\text { The Cloud Lounge \& Dining } \\
\text { Jakarta }\end{array}$ & Lantai $46 \& 49$ \\
\hline 2 & SKYE Bar \& Restaurant & $\mathrm{La}$ \\
\hline 3 & Henshin & Lantai $67-69$ \\
\hline
\end{tabular}

Sumber: Hasil Temuan Peneliti 2018

Berdasarkan latar belakang tersebut maka penelitian ini ingin mengangkat tentang perkembangan produk wisata yang ditawarkan di daya tarik wisata kuliner berbasis rooftop restaurant and bar.

\section{TINJAUAN PUSTAKA}

Konsep yang berkaitan dengan rumusan masalah pertama, yaitu mengenai produk pariwisata yang ditawarkan. Produk pariwisata adalah suatu susunan produk yang terpadu, yang disediakan oleh perusahaan dan ditawarkan secara terpisah untuk dinikmati oleh wisatawan. Produk tersebut terdiri dari 3 (tiga) unsur, yaitu daya tarik wisata (citra yang diharapkan oleh wisatawan), fasilitas (akomodasi, usaha pengolahan makanan, parkir, transportasi, dan rekreasi atau hiburan), dan aksesibilitas atau kemudahan yang diberikan oleh daerah tujuan wisata.

Konsep kedua yang berkaitan dengan penelitian ini yaitu teori wisata perkotaan merupakan sekumpulan sumber daya atau kegiatan wisata yang berlokasi di kota yang ditawarkan kepada pengunjung yang berasal dari tempat lain, yang biasa disebut wisatawan atau pelancong. Namun, saat ini konsep wisata perkotaan dikembangkan lagi menjadi 5 (lima) konsep, yaitu: Tourist Historic City (Kota Sejarah), Cultural City (Kota Budaya), Fantasy City (Kota Fantasi), Creative City (Kota Kreatif) dan Urban Ecotourism (Kota Berbasis Lingkungan). Tujuan digunakannya konsep wisata perkotaan pada penelitian ini adalah untuk memperkuat bahwa rooftop restaurant dan bar merupakan salah satu daya tarik pada wisata perkotaan.

\section{METODE PENELITIAN}

Ruang lingkup penelitian mengenai produk pariwisata yang ditawarkan oleh 
daya tarik wisata kuliner berbasis rooftop restaurant and bar dan mengenai perkembangan rooftop restaurant and bar dari awal dibuka untuk umum sampai saat ini. Terdapat 3 (tiga) lokasi rooftop restaurant and bar yang digunakan dalam penelitian ini, yaitu di The Cloud Lounge \& Dining Jakarta, SKYE Bar \& Restaurant, dan Henshin. Pengumpulan data menggunakan teknik observasi partisipan yaitu peneliti langsung ke mengamati, dan ikut serta dalam kegiatan yang terdapat di lokasi penelitian untuk mendapatkan data mengenai kegiatan yang dapat dilakukan, dan produk apa saja yang ditawarkan oleh rooftop restaurant and bar. Peneliti menggunakan purposive sampling atau judgemental sampling dalam menentukan informan. Dalam penelitian ini, yang menjadi sampel adalah manager dan supervisor dari rooftop restaurant and bar di ketiga lokasi penelitian. Teknik analisis data adalah deskriptif kualitatif dan fishbone analysis. Deskriptif kualitatif digunakan dalam penelitian ini untuk mendeskripsikan gambaran umum mengenai rooftop restaurant and bar, produk pariwisata yang ditawarkan, serta penjelasan mengenai perkembangan rooftop restaurant and bar berdasarkan periode, sedangkan fishbone analysis digunakan untuk mencari sebab dan akibat adanya perkembangan dalam rooftop restaurant and bar.

\section{HASIL DAN PEMBAHASAN}

Pada umumnya, bagian atas atau atap dari sebuah gedung tidak memiliki nilai kegunaan atau biasanya dikosongkan. Melihat dari hal ini terciptalah sebuah inovasi atau terobosan baru yang tidak terpikirkan sebelumnya yaitu membuat dan menjadikan restoran dan bar diatas atau bagian atap gedung tersebut dengan tujuan untuk memberikan kesan yang berbeda bagi para pengunjungnya. Terdapat 3 (tiga) lokasi yang dijadikan sebagai tempat observasi dalam penelitian ini, lokasi tersebut adalah The Cloud Lounge \& Dining Jakarta, SKYE Bar \& Restaurant, dan Henshin

\section{a. Produk Pariwisata yang di Tawarkan oleh Wisata Kuliner Berbasis Rooftop Restaurant and Bar}

Magnet atau daya tarik wisata dalam penelitian ini merupakan wisata buatan atau hasil karya manusia, selanjutnya fasilitas yang diterangkan adalah transportasi, rekreasi dan hiburan, parkir, akomodasi, pengelolaan makanan, serta lain sebagainya. Aksesibilitas yang diterangkan adalah bagaimana cara pengunjung dari kota asal mereka memiliki atau tersedianya akses untuk berkunjung ke rooftop restaurant and bar.

Produk-produk pariwisata yang disuguhkan oleh The Cloud Lounge \& Dining Jakarta adalah panorama dan pemandangan Kota Jakarta dari ketinggian lantai 49 yang dapat dilihat dengan baik dan santai serta dilanjutkan dengan menyantap kuliner atau hidangan Western dan Indonesian food, ditambah dengan mengabadikan setiap kejadian dan momen bersama dengan berfoto yang dilengkapi dengan indahnya pemandangan saat matahari terbenam. The Cloud Lounge \& Dining Jakarta juga dilengkapi dengan vodka room, yang memiliki karakteristik suhu ruangan yang mencapai $2^{\circ}$ celcius, sehingga pengunjung dapat menikmati sensasi situasi dan suasana khas seperti berada di Eropa bagian Timur. Untuk waktu beroperasinya bagian Lounge dimulai dari pukul 16.00 sampai dengan 02.00 WIB setiap harinya. Untuk waktu operasi restoran dimulai dari pukul 18.00 sampai dengan pukul 22.30 WIB. Terdapat beberapa peraturan terkait dengan pakaian yang dikenakan saat berkunjung dimana para pengunjung diwajibkan untuk mengenakan pakaian yang sopan dengan tema smart casual. Selain itu, komitmen untuk pengunjung dengan kriteria umur 18 tahun keatas juga diberlakukan dengan ketat yaitu pengunjung diharapkan untuk memperlihatkan atau menunjukkan identitas diri sebelum memasuki The Cloud Lounge \& Dining Jakarta.

Selanjutnya adalah SKYE Bar \& Restaurant. Produk pariwisata yang 
ditawarkan diantaranya adalah pemandangan kota Jakarta dari ketinggian. SKYE Bar \& Restaurant berlokasi di lantai 56. SKYE Bar \& Restaurant memiliki perbedaan peraturan terhadap pakaian yang digunakan oleh pengunjung. Pengunjung diperkenankan masuk dengan berpakaian santai akan tetapi tidak diperkenankan menggunakan sandal. Selain itu, perbedaan lainnya terletak pada peraturan terkait umur para pengunjung dimana pada SKYE Bar \& Restaurant tidak memeriksa kartu identitas, tetapi dihimbau agar tidak membuat kegaduhan atau keributan. Untuk waktu operasinya dimulai pada pukul 16.00 sampai dengan pukul 01.00 WIB. Selanjutnya untuk akhir pekan dan hari libur nasional waktu beroperasi dimulai dari pukul 16.00 sampai dengan pukul $02.00 \mathrm{WIB}$, dan khusus restoran pada akhir pekan beroperasi mulai dari pukul 12.00 WIB.

Henshin menawarkan produk pariwisata yang memberikan dan menyajikan pemandangan Kota Jakarta secara menyeluruh, hal ini dikarenakan Henshin merupakan rooftop restaurant and bar yang tertinggi di Jakarta, bahkan bisa dikatakan tertinggi di Indonesia. Henshin berlokasi di lantai 67 sampai 69 Gamma Tower, Hotel The Westin Jakarta, yang dimana Gamma Tower memiliki tinggi bangunan mencapai 288,6 meter. Selain disuguhkan potret kota Jakarta, pengunjung juga dapat mengambil dan mengabadikan setiap momen dan situasi bersama keluarga, pasangan, dan kerabat, dengan dilanjutkan menyantap dan menikmati makan malam yang bertemakan fusion antara Japanese food dan Peruvian food. Henshin mulai beoperasi pada pukul 17.00 sampai dengan pukul 00.00 WIB pada hari kerja dan pukul 17.00 sampai dengan pukul 02.00 WIB pada akhir pekan.

\section{b. Perkembangan Rooftop Restaurant and Bar dari Awal di Buka Sampai Saat Ini}

SKYE Bar \& Restaurant merupakan pioneer dari inovasi rooftop restaurant and bar yang terletak atau berlokasi di lantai 56 BCA Tower yang diawali pembukaannya pada tahun 2012. Sebagai pioneer maka tidak lepas pula dari munculnya para pesaing-pesaing, hal ini terbukti dari munculnya The Cloud Lounge \& Dining Jakarta yang terletak atau beroperasi pada lantai 46 dan 49 gedung The Plaza. Selain The Cloud Lounge \& Dining Jakarta muncul juga pesaing yang baru beroperasi pada tahun 2017 yaitu Henshin. Henshin adalah rooftop restaurant \& bar yang memiliki ciri khas tersendiri yaitu merupakan rooftop restaurant \& bar yang tertinggi di Indonesia yang beroperasi di lantai 67 sampai 69 Gama Tower. Terdapat beberapa perubahan-perubahan yang dilakukan oleh masing-masing usaha yang disesuaikan dengan perkembangan pasar. Diharapkan dengan perubahan-perubahan ini dapat memberikan efek positif bagi jumlah kunjungan dan kegiatan operasional usaha lainnya. Mengenai hal tersebut maka pembahasan ini akan lebih mendalami pada perkembangan yang terjadi dan dilakukan oleh The Cloud Lounge \& Dining Jakarta, SKYE Bar \& Restaurant, dan Henshin dengan menggunakan fishbone analysis.

\section{c. Perkembangan The Cloud Lounge \& Dining Jakarta}

The Cloud Lounge \& Dining Jakarta mulai beroperasi pada bulan Juli 2013. Dalam proses perkembangannya telah terjadi beberapa kali perubahan-perubahan baik itu perubahan pada fisik usaha maupun non-fisik dari usaha. Pada Gambar 1 dipaparkan mengenai proses perubahan serta perkembangan yang dilakukan oleh The Cloud Lounge \& Dining Jakarta dengan menggunakan gambar fishbone.

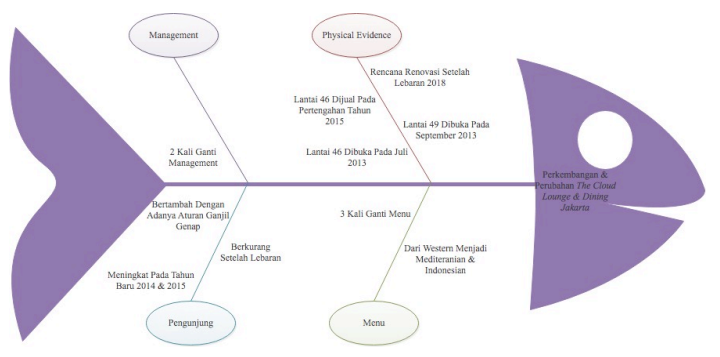

Gambar 1. Fishbone Analysis Perkembangan The Cloud Lounge \& Dining Jakarta Sumber : Hasil Penelitian 2018 
Fokus pembahasan terletak pada physical evidence, sejak pertama kali beroperasi The Cloud Lounge \& Dining Jakarta terdapat 1 lantai yang dioperasikan yaitu lantai 46, selanjutnya terjadi pengembangan sehingga diresmikan lagi 1 lantai baru dan dapat beroperasi pada lantai 49. Bapak Arief yang merupakan manager dari The Cloud Lounge \& Dining Jakarta, menerangkan bahwa diresmikannya lantai 49, menjadikan lantai 46 sebagai ruangan untuk acara yang lebih bersifat private, sedangkan lantai 49 dioperasikan sebagai rooftop restaurant \& bar untuk umum.

Tetapi memasuki pergantian semester di tahun 2015 lantai 46 tersebut dijual kepada restoran Jepang yang bernama Momozen, alasan pihaknya menjual dikarenakan berbagai macam masalah operasional dan alasan lainnya yang tidak dapat diterangkan secara langsung dan detail. Dalam perjalanannya The Cloud Lounge \& Dining Jakarta, rooftop restaurant \& bar sudah dua kali melakukan pergantian manajemen. Selain melakukan pergantian manajemen terdapat juga perubahan pada menu makanan dan minuman, Berdasarkan penuturan dari pihak manajer bahwa sudah tiga kali melakukan perubahan pada daftar menu hal ini dilakukan untuk memberikan variasi pada konsumen agar konsumen tidak merasa bosan dan jenuh. Perubahanperubahan menu yang dilakukan mulai dari tema Western sampai Mediterranean dan Indonesian.

Terhadap jumlah kunjungan tercatat peningkatan yang cukup drastis yang terjadi pada setiap tahun baru, hal ini terjadi karena The Cloud Lounge \& Dining Jakarta membuat acara-acara yang menarik sehingga mampu menarik minat konsumen untuk berkunjung dan menikmati suasana yang telah disiapkan. Selain pada setiap akhir tahun, peningkatan jumlah kunjungan juga terjadi dikarenakan aturan pemerintah daerah yaitu system atau aturan ganjil-genap, sehingga umumnya pengunjung data untuk menghabiskan waktu dan bersantai sembari menunggu berakhirnya aturan tersebut.

\section{d. Perkembangan SKYE Bar \& Restaurant}

Perkembangan yang terjadi pada $S K Y E$ Bar \& Restaurant tidak terdapat perubahan yang cukup signifikan terutama dalam hal fisik usaha. Berdasarkan penuturan dari Bapak Radit yang merupakan manager SKYE Bar \& Restaurant, dijelaskan bahwa dari awal berdirinya usaha ini perkembangan atau perubahan secara fisik belum dilakukan atau dapat dikatakan masih asli atau original. Perubahan memang tidak terjadi pada fisik usaha, melainkan perubahan lebih difokuskan pada perubahan peraturan, menu, harga makanan dan minuman, serta lain sebagainya. Perubahan-perubahan yang telah dilakukan mampu memberikan hasil yang positif pada tingkat kunjungan konsumen, khususnya perubahan yang dirasa memberikan dampak yang lebih besar adalah adanya perubahan pada peraturan usaha. Pada Gambar 2 dipaparkan dan dijelaskan mengenai perkembangan yang terjadi dan perubahanperubahan yang sudah dilakukan, Gambar 2 disajikan dalam bentuk gambar fishbone.

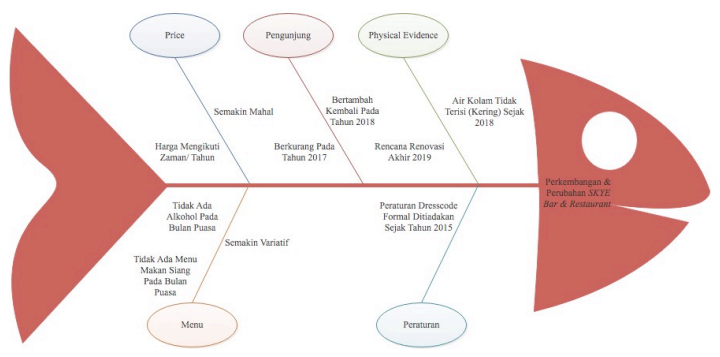

Gambar 2. Fishbone Analysis Perkembangan SKYE Bar \& Restaurant

Sumber : Hasil Penelitian 2018

Berdasarkan hasil tersebut bahwa perubahan secara fisik usaha tidak menunjukkan hal yang signifikan, konsep dan desain usaha masih dipertahankan keasliannya, tetapi berdasarkan pengamatan yang dilakukan bahwa terdapat sedikit perubahan kecil pada kolam yang terletak di bar. Sejak mulai dioperasikan, yang paling menjadi perhatian khusus bagi konsumen atau yang sangat dikenal adalah aturan tentang pakaian yang wajib dikenakan. Mulanya pengunjung diwajibkan untuk mengenakan pakaian yang rapi dan formal, 
tetapi dengan pelaksanaan peraturan ini membuat kegelisahan bagi para pengunjung yang tergolong kriteria menengah, sehingga pada tahun 2015 peraturan terkait pakaian yang dikenakan mulai tidak diberlakukan lagi. Dengan diberlakukannya peraturan baru ini memberikan dampak yang positif khususnya terhadap peningkatan kunjungan tamu. Seiring dengan perjalanan usaha terjadi peningkatan dan penurunan jumlah kunjungan konsumen, hal ini menjadi sesuatu yang wajar dalam kegiatan usaha. Selain itu berbagai kebijakan lainnya pun turut dilakukan diantaranya pada harga dan daftar menu.

\section{e. Perkembangan Henshin}

Perkembangan usaha yang terjadi pada Henshin tergolong mulai menunjukkan kearah yang positif, walaupun Henshin masih tergolong rooftop restaurant and bar yang baru beroperasi tetapi mencapai prestasi ini merupakan sebuah kebanggaan bagi pihak manajemen Henshin. Gambar 3 dipaparkan dan dijelaskan bagaimana proses perkembangan Henshin yang mampu mencapai prestasi dan perkembangan yang sangat positif.

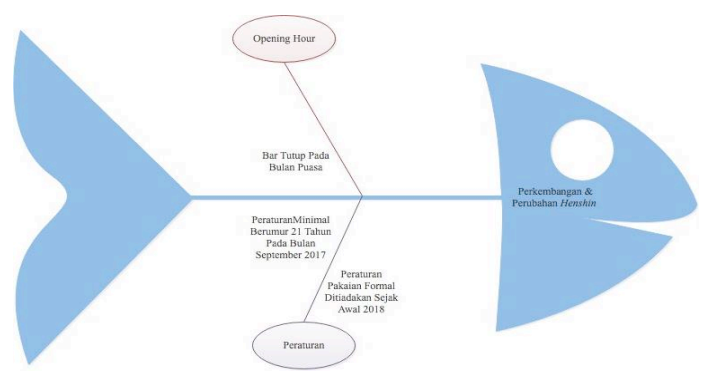

\section{Gambar 3. Fishbone Analysis Perkembangan Henshin}

Sumber : Hasil Penelitian 2018

Berbagai perubahan-perubahan terus dilakukan oleh manajemen Henshin, yang menjadi fokus manajemen adalah terkait peraturan batasan usia yang boleh masuk kedalam Henshin. Terjadi pengetatan peraturan batas usia yang boleh masuk yaitu konsumen atau pengunjung yang berusia kurang dari 21 tahun tidak diizinkan untuk masuk, berbagai tindakan preventif pun turut dilakukan seperti pengecekan kartu identitas pengunjung. Selain perubahan peraturan pada kriteria usia, terjadi perubahan juga pada peraturan terkait busana atau pakaian yang dikenakan, dimana yang sebelumnya diwajibkan mengenakan busana formal. Perubahan tersebut dilakukan agar konsumen atau pengunjung dapat merasa senang dan nyaman, sehingga hal ini akan berdampak pada tingkat kunjungan konsumen.

\section{SIMPULAN DAN SARAN Simpulan}

Berdasarkan dari pengamatan, hasil penelitian yang diperoleh, serta pembahasan yang telah dilakukan, maka dapat peneliti simpulkan bahwa produk-produk pariwisata yang disuguhkan oleh The Cloud Lounge \& Dining Jakarta adalah panorama dan pemandangan Kota Jakarta dari ketinggian lantai 49, dilanjutkan dengan menyantap kuliner atau hidangan Western dan Indonesian food serta ditambah dengan mengabadikan setiap kejadian dan momen bersama dengan berfoto yang berlatarbelakang pemandangan saat matahari terbenam. The Cloud Lounge \& Dining Jakarta juga dilengkapi dengan vodka room, yang memiliki karakteristik suhu ruangan yang mencapai $-2^{\circ}$ celcius, sehingga pengunjung dapat menikmati sensasi situasi dan suasana khas seperti berada di Eropa bagian Timur.

Selanjutnya adalah SKYE Bar \& Restaurant menawarkan produk pariwisata yang diantaranya adalah pemandangan kota Jakarta dari ketinggian. SKYE Bar \& Restaurant berlokasi di lantai yang lebih tinggi, yaitu lantai 56. SKYE Bar \& Restaurant memiliki perbedaan peraturan terhadap pakaian yang digunakan oleh pengunjung. Pengunjung diperkenankan masuk dengan berpakaian santai akan tetapi tidak diperkenankan menggunakan sandal. Selain itu pada SKYE Bar \& Restaurant tidak memeriksa kartu identitas, tetapi dihimbau agar tidak membuat kegaduhan atau keributan. 
Henshin menawarkan produk pariwisata yang memberikan dan menyajikan pemandangan Kota Jakarta secara menyeluruh. Selain disuguhkan potret kota Jakarta, pengunjung juga dapat mengambil dan mengabadikan setiap momen dan situasi bersama keluarga, pasangan, dan kerabat, dengan dilanjutkan menyantap dan menikmati makan malam yang bertemakan fusion antara Japanese food dan Peruvian food.

The Cloud Lounge \& Dining Jakarta telah melakukan beberapa kali perubahanperubahan baik itu perubahan pada fisik usaha maupun non-fisik. Fokus pembahasan terletak pada physical evidence, selain itu terdapat beberapa keputusan operasional manajemen yang telah dilakukan seperti perubahan dan pergantian manajemen dan melakukan perubahan dan inovasi pada daftar menu.

Perkembangan yang terjadi pada SKYE Bar \& Restaurant tidak terdapat perubahan yang cukup signifikan terutama dalam hal fisik usaha. Perubahan memang tidak terjadi pada fisik usaha, melainkan perubahan lebih difokuskan pada perubahan peraturan, menu, harga makanan dan minuman, serta lain sebagainya. Perubahan-perubahan yang telah dilakukan mampu memberikan hasil yang positif pada tingkat kunjungan konsumen,

Perkembangan usaha yang terjadi pada Henshin tergolong mulai menunjukkan kearah yang positif, walaupun Henshin masih tergolong rooftop restaurant \& bar yang baru beroperasi tetapi mencapai prestasi ini merupakan sebuah kebanggaan bagi pihak manajemen Henshin. Berbagai perubahan telah dilakukan oleh manajemen Henshin diantaranya terkait peraturan batasan usia yang boleh masuk kedalam Henshin. Selain perubahan peraturan pada kriteria usia, terjadi perubahan juga pada peraturan terkait busana atau pakaian yang dikenakan. Perubahan tersebut dilakukan agar konsumen atau pengunjung dapat merasa senang dan nyaman, sehingga hal ini akan berdampak pada tingkat kunjungan konsumen.
Saran

telah $\begin{gathered}\text { Beradasarkan hasil penelitian yang } \\ \text { diperoleh maka peneliti }\end{gathered}$ merekomendasikan tiga saran yang diharapkan mampu menjadi masukan bagi pelaku bisnis pariwisata, bagi pihak manajemen, bagi pihak pemerintah, dan bagi peneliti selanjutnya. Ketiga saran tersebut adalah:

1. Pengusaha rooftop restaurant and bar di Indonesia disarankan untuk mengangkat tema kebudayaan daerah asal atau budaya Indonesia secara keseluruhan yang dapat dikemas dengan lebih modern. Karena berdasarkan fenomena dilapangan bahwa sebagian besar dekorasi rooftop restaurant and bar $\mathrm{di}$ Indonesia bertemakan luar negeri atau kebudayaan asing, selain dari segi dekorasi makanan dan minumannya pun diharapkan mampu menyesuaikan dengan tema kebudayaan Indonesia. Karena sejatinya kebudayaan Indonesia yang dikemas dengan modern akan memberikan nilai tambah yang unik dan positif bagi perkembangan rooftop restaurant and bar.

2. Pemerintah disarankan untuk memberikan atau membuat rooftop restaurant and bar resmi yang tentunya disesuaikan dengan peraturan pemerintah yang berlaku agar mampu menjadi magnet dan inovasi wisata kuliner Indonesia yang baru, khususnya pada wilayah perkotaan yang umumnya memiliki keterbatasan sumber daya alam dan budaya. Inovasi rooftop restaurant and bar diharapkan mampu memberikan terobosan dan tambahan wisata baru diperkotaan, sehingga pengunjung memiliki tambahan aktivitas yang dapat dilakukannya diperkotaan. Rooftop restaurant and bar juga tidak hanya menyasar pada wisatawan yang berkunjung saja, tetapi juga menyasar kaum millennial yang merupakan pasar yang sangat potensial saat ini, serta bagi masyarakat setempat. Untuk menjalankan setiap kegiatan ini maka 
kegiatan promosi menjadi hal yang sangat penting untuk dilakukan, berbagai macam media harus lebih dimaksimalkan dan dioptimalkan seperti melalui media cetak, elektronik, serta pemanfaatan media online seperti sosial media.

3. Bagi peneliti selanjutnya disarankan untuk mengembangkan penelitian ini dengan menambahkan serta mendalami strategi pemasaran yang dilakukan oleh rooftop restaurant and bar sehingga mampu untuk menjadi potensi wisata baru. Selanjutnya diharapkan untuk membahas dan mendalami mengenai prediksi perkembangan rooftop restaurant and bar di dalam perkembangan dan persaingan usaha saat ini, serta meneliti pula mengenai dampak sosial, ekonomi, dan lingkungan yang dihasilkan dari beroperasinya rooftop restaurant and bar.

\section{DAFTAR PUSTAKA}

Ashworth G. J., dan Tunbridge, J. E. (1990). The Tourist-Historic City, John Wiley \& Sons, England.

Damodar N., Gujarati, dan Dawn C. P. (2009). Basic Econometric 5th Edition. McGraw -Hill: New York.

Page, S. J. dan Hall, M. C., (2003). Managing Urban Tourism, Pearson Education Limited, Harlow.

Richard, G. dan Wilson, J. (2007). Tourism, Creativity, and Development, Routledge, Oxon.

Tague, N. R. (2005). The Quality Toolbox. (2th edition). Milwaukee, Wisconsin: ASQ Quality Press

Undang-Undang Republik Indonesia No.10 Tahun 2009 Tentang Kepariwisataan

Yoeti, A. O. (1996). Pengantar Ilmu Pariwisata Edisi Revisi. Bandung. Penerbit Angkasa. 